\title{
Knowledge, Perception and Practice of Mothers/Caretakers and Family's regarding Child Nutrition (under 5 years of age) in Nekemte Town, Ethiopia
}

\author{
Wondu Garoma Berra
}

Department of Food Technology and Process Engineering, College of Engineering and Technology Wollega University, PO Box: 395, Nekemte, Ethiopia

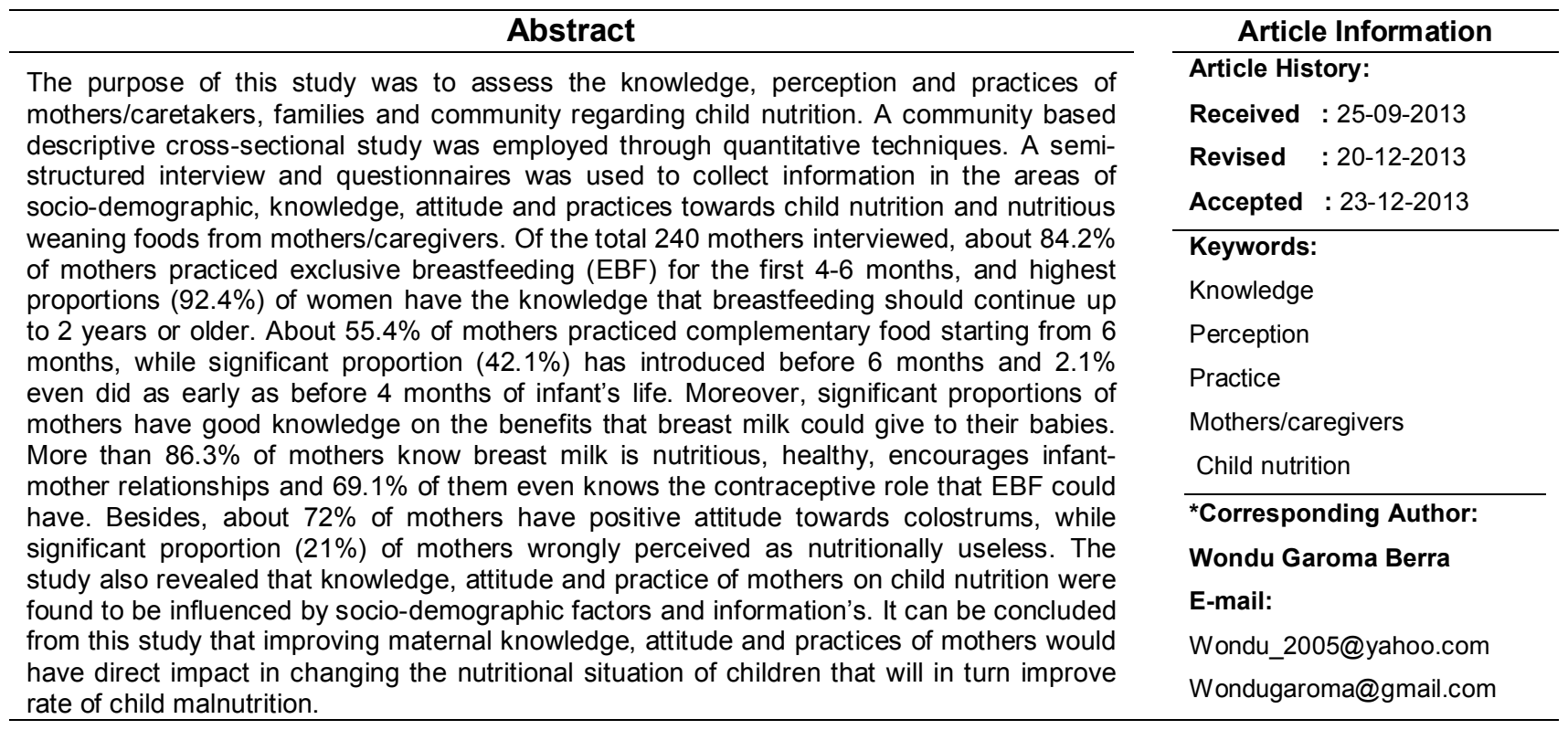

\section{INTRODUCTION}

Malnutrition among children is one of the most challenging and complex global problem (Waqar Azim et al., 2005; Gericke Gerdsa, 2004), affecting development particularly that of under privileged and the poor. Over 6 million death (55\% of the 12 million children under 5 years of age) each year in developing countries from infectious diseases can be attributed to malnutrition bringing nutrition to the forefronts of national and international concern (Waqar Azim et al., 2005; Sendeku and Agegnehu, 2007; Ethiopia National Nutrition Strategy 2009). In Ethiopia malnutrition is responsible for $57 \%$ of mortality of under-five children despite the impressive increase in food production indicating that supply alone is not a sufficient response (Sendeku and Agegnehu, 2007; FMOH protocol, 2007). Although, the factors associated with the problem of malnutrition vary from place to place in the country, the complex sets includes inappropriate dietary intake, infectious diseases, socioeconomic factors, lack of knowledge of mothers and inadequate or inattentive care of young children on nutritional need
(Sendeku and Agegnehu, 2007; Langi and Grace, 2008; Gemeda et al., 2013).

There is a growing realization that a healthful diet particularly in the first few years of life are of paramount importance in laying the foundation of good health (Anyango and Ayeieko, 2011). However, these areas commonly have received little development support.

According to Awogobenja et al., (2010) amongst the effective measures for reducing mortality in children less than 5 years of age, promotion of exclusive breastfeeding (EBF) and improved complementary food (CF) at proper age has been ranked first and third respectively by the World Health Organization. WHO and United Nations Children's Fund (UNICEF) recommend breast feeding to be started immediately following delivery for the baby to get colostrums (Petit, 2008). The infant should thereafter be exclusively breastfed for the first 4 to 6 months of life on child's demand with no other fluids including water, 


\section{Wondu Garoma Berra}

and breastfeeding should continue together with weaning food up to and beyond second year of life. However, infant feeding and weaning practices have cultural, social and economical roots making malnutrition more than a medical problem. It has been indicated in many studies all over the world that these practices are the subjects strongly influenced by customs, beliefs, superstitions, religion, cultural pattern, mother's education and socioeconomic status of the family.

Despite the fact breastfeeding in known to be the best way to feed infant by providing the psychological and health benefit to both the mother and child, globally there has been a general decline in the practice of breastfeeding both in terms of prevalence and duration in the past few decades (Singh, 2010; Petit, 2008). The possible reasons for declining breastfeeding includes lack of confidence that the child is getting enough, increased urban women work load demand that makes them to be separated from their babies for longer hours, decline in social support, discomfort on breastfeeding in public, and intense promotion of commercial milk formulae.

Therefore, investigating of the knowledge, perception and practice of mothers/caretakers, family and motivation of community at large is so critical as the first few years of life are of paramount importance in laying foundation for sustainable improvements in child health. Besides, the present study would enable governments and other concerned bodies to design appropriate nutrition education program and adequate complementary food to improve child survival. The major objectives of this study are therefore to assess the nutritional knowledge, perception and practices of mothers/caretakers, familys and community on child nutrition.

\section{MATERIALS AND METHOD}

\section{Study Design}

This study was conducted in Nekemte town, Oromia region (Ethiopia) between April and June 2012. In this survey design, a community based descriptive crosssectional study was employed through quantitative techniques. A semi-structured interview and questionnaires was used to collect information in the areas of socio-demographic, knowledge, attitude and practices towards child nutrition and nutritious weaning foods were obtained from mothers/caregivers. The questionnaire was mainly of the closed type except for few open type questions which were designed to allow the mother express their ideas on certain issues. A total of 240 mothers of infants 0-59 months were interviewed. Preparation for field data collection has included training of interviewers and pre-testing of questionnaires.

\section{Sample Size}

The sample size of the study was determined by considering the prevalence of recent previous similar study at different place (Arbaminch town, Ethiopia), which was reported as $15.1 \%$ of mothers had good nutritional knowledge, and $16.1 \%$ of mothers had good nutritional practices. For this study the prevalence that give larger sample size, along with $95 \%$ confidence level and $1 \%$ tolerable error was considered.
Sci. Technol. Arts Res. J., Oct-Dec 2013, 2(4): 78-86

Accordingly, a minimum required sample size $(\mathrm{N})$ was calculated in study designed to measure a characteristic in terms of a proportion as follows,

$$
N=\frac{4(\mathrm{Zcrit})^{2} p(1-p)}{D^{2}}
$$

Where $p$ is a pre-study estimate of the proportion to be measured, $\mathrm{N}$ the sample size of the single study group, the Zcrit is 1.960 given in table and $D$ is the total width of the expected $\mathrm{Cl}$. About $10 \%$ is considered for non response.

$$
N=\frac{4(1.960)^{2} 0.161(1-0.161)}{(0.01)^{2}}=210+10 \%
$$

Non-response $\approx 231$

Therefore, a minimum of 231 mothers and/or caretakers of infants $0-59$ months were examined for this particular study.

\section{Sampling Procedures}

Nekemte town has been divided into 6 self administrations called "Kifle-astedader/kuta bulchinsa" namely: Bekenisa kassie, Cheleki, Burka jato, Dergie, Bekie jama and Kassie. Each of the self-administration has 14-25 clusters ("got"). Again, each "got" has been further sub clustered to 40-74 called "Gare". A multistage cluster sampling was used to select the study population. Accordingly, out of the 6 self-administration areas in the town, 4 were selected randomly using lottery method. The selected administrations have 14 to 25 clusters (got) consisting of 90 to 120 households each. From each self administration 2 clusters (got) or a minimum of 60 households were randomly chosen. A total of 8 clusters ("got") or 240 households were selected. A pen was spun at the center of the cluster and starting from the direction the pen pointed every household were visited, mothers having at least one under five child was interview serially until the required sample size is obtained in each cluster. In case there was more than one mother having under five children in a single household, only one mother was selected by lottery method. Again if there was more than one child in the household the index child is the younger one.

\section{Data Processing and Analysis}

The data collected were edited, coded and analyzed for common themes. All the data that were generated by this study were entered into SPSS worksheet and analysis was done using the SPSS computer software package (SPSS+ version 20). Data values were checked against the field records to ensure that no data entry errors were made. Findings were statistically analyzed for frequency, descriptive statistics, correlation and chisquare to evaluate associations between dependant and independent variables using the statistical package against the significance level that was set at $p<0.05$.

\section{Ethical Consideration}

The study received ethical approval from Wollega University. The objectives of the study were elucidated for the interviewees to decide whether to participate in the study or not. The interview process was conducted with adequate confidentiality by approaching and interviewing each participant separately, and without revealing names of the interviewees. 


\section{RESULTS}

\section{Characteristic of Respondents}

In this particular study a total of 240 mothers/ caregivers were participated in the individual questionnaire interview and out of which 3 questionnaires were excluded from the analysis because of incomplete response (making the response rate of $98.8 \%$ ). Of the 237 women interviewed (Table 1), about 226 (95.4\%) were biological mothers. With respect to age, participation of respondents was highest (57.1\%) among mothers aged between 25 to 34 years. About $79.9 \% \quad(n=187)$ of respondents were Oromo, $80.8 \%(n=194)$ were Christian, $94.2 \%(n=226)$ were married and approximately about $34.2 \%(n=82)$ had attended at least some sort of tertiary education. Moreover, 39\% $(n=81)$ of the respondents were employed and $52.6 \%(n=126)$ has earned a monthly family income above one thousands Ethiopian Birr.

Table 1: Socio-demographic Characteristic of Respondents.

\begin{tabular}{|c|c|c|c|}
\hline \multicolumn{2}{|c|}{ Variables } & Frequency $(n=237)$ & Percent \\
\hline \multirow{5}{*}{ Age (in years) } & $15-24$ & 32 & 13.3 \\
\hline & $25-34$ & 137 & 57.1 \\
\hline & $35-50$ & 60 & 25.0 \\
\hline & $\geq 50$ & 8 & 3.3 \\
\hline & & Frequency $(n=237)$ & Percent \\
\hline \multirow{4}{*}{ Ethnic Category } & Oromo & 187 & 77.9 \\
\hline & Amhara & 42 & 17.5 \\
\hline & Tigre & 5 & 2.1 \\
\hline & Other & 2 & 0.8 \\
\hline \multirow{4}{*}{ Religion Category } & & Frequency $(n=234)$ & Percent \\
\hline & Christian & 194 & 80.8 \\
\hline & Museum & 37 & 15.4 \\
\hline & Others & 3 & 1.3 \\
\hline \multirow{8}{*}{ Education Status } & & Frequency $(n=237)$ & Percent \\
\hline & Illiterate & 13 & 5.4 \\
\hline & Read \& write & 20 & 8.3 \\
\hline & Grade 1-6 & 25 & 10.4 \\
\hline & Grade $7-8$ & 46 & 19.2 \\
\hline & Grade 9-12 & 51 & 21.3 \\
\hline & Certificate/College & 64 & 26.7 \\
\hline & University & 18 & 7.5 \\
\hline \multirow{3}{*}{ Employment Status } & & Frequency $(n=237)$ & Percent \\
\hline & No & 156 & 65.0 \\
\hline & Yes & 81 & 33.8 \\
\hline \multirow{5}{*}{ Family income } & & Frequency $(n=232)$ & Percent \\
\hline & Less than 450 & 49 & 20.4 \\
\hline & $450-999$ & 57 & 23.8 \\
\hline & $1000-1500$ & 57 & 23.8 \\
\hline & Above 1500 & 69 & 28.8 \\
\hline \multirow{6}{*}{ Marital Status } & & Frequency $(n=237)$ & Percent \\
\hline & Unmarried & 4 & 1.7 \\
\hline & Married & 226 & 94.2 \\
\hline & Divorced & 3 & 1.3 \\
\hline & Widowed & 2 & 0.8 \\
\hline & Other & 1 & 0.4 \\
\hline
\end{tabular}

\section{Mothers Knowledge, Attitude and Practices on Infant Feeding}

Generally, table 2 shows the type of milk feeding, duration of exclusive breastfeeding, and age and type of complementary feeding commonly practiced among mothers in Nekemte town. The data in this table presented that, breast milk and/or cow milk or both together $(85 \%, n=204)$ are the dominant type of milk feeding practiced among mothers in this town. With regard to breast feeding, about $84.2 \%(n=192)$ mothers practiced EBF up to the first 6 months, while the remaining $15.8 \%$ even practices after 6 months. However, this figure may not show the proportion of mothers who EBF for exactly 6 months. Surprisingly, highest proportion of mothers $(92.4 \%, n=206)$ believed that breastfeeding should continue up to 2 years or older together with additional foods.

Furthermore, figure 1 revealed that about $55.4 \%$ of mothers had introduced additional food within the age duration of 6 to 12 months. This study also showed that a considerably significant proportion of mothers $(42.1 \%)$ had introduced complementary food within 4-6 months and even about $2.1 \%$ of mothers did before 4 months of baby's life. As portrayed in table 2 approximately about $62.4 \% \quad(n=154)$ of respondents had used cow milk, porridge and gruel as complementary food for their children. 
Table 2: Infant feeding practices among respondents

\begin{tabular}{|c|c|c|c|c|}
\hline \multicolumn{2}{|c|}{ Variables } & Frequency $(n=237)$ & Percent & Valid Percent \\
\hline \multirow{5}{*}{$\begin{array}{l}\text { Type of Milk Feeding } \\
\text { Practices }\end{array}$} & Breast milk alone & 92 & 38.3 & 38.3 \\
\hline & Breast milk + cow milk & 112 & 46.7 & 46.7 \\
\hline & Breast milk + formula & 12 & 5.0 & 5.0 \\
\hline & Formula alone & 2 & 0.8 & 0.8 \\
\hline & Mixed type & 16 & 6.7 & 6.7 \\
\hline & & Frequency $(n=228)$ & Percent & Valid Percent \\
\hline \multirow{4}{*}{ Duration of EBF } & Up to 6 months & 192 & 80.0 & 84.2 \\
\hline & 6-12 months & 23 & 9.6 & 10.1 \\
\hline & $12-23$ months & 7 & 2.9 & 3.1 \\
\hline & Above 24 months & 6 & 2.5 & 2.6 \\
\hline & & Frequency $(n=233)$ & Percent & Valid Percent \\
\hline \multirow{4}{*}{$\begin{array}{l}\text { Age of introduction of } \\
\text { complementary feeding }\end{array}$} & Before 4 months & 5 & 2.1 & 2.1 \\
\hline & 4-6 months & 98 & 40.8 & 42.1 \\
\hline & $6-12$ months & 129 & 53.8 & 55.4 \\
\hline & After 1 year & 1 & 0.4 & 0.4 \\
\hline & & Frequency $(n=237)$ & Percent & Valid Percent \\
\hline \multirow{5}{*}{$\begin{array}{c}\text { Type of } \\
\text { Complementary Food }\end{array}$} & Cow milk, porridge and gruel & 154 & 64.2 & 64.2 \\
\hline & Cow milk alone & 19 & 7.9 & 7.9 \\
\hline & Mashed food & 5 & 2.1 & 2.1 \\
\hline & Milk \& gruel & 2 & 0.8 & 0.8 \\
\hline & Mixed feeding & 52 & 21.7 & 21.7 \\
\hline & & Frequency $(n=223)$ & Percent & Valid Percent \\
\hline \multirow{3}{*}{ Bf should continue } & 2 years or older & 206 & 85.8 & 92.4 \\
\hline & Only the first 6 months & 4 & 1.7 & 1.8 \\
\hline & Only 1 year or lower & 13 & 5.4 & 5.8 \\
\hline
\end{tabular}

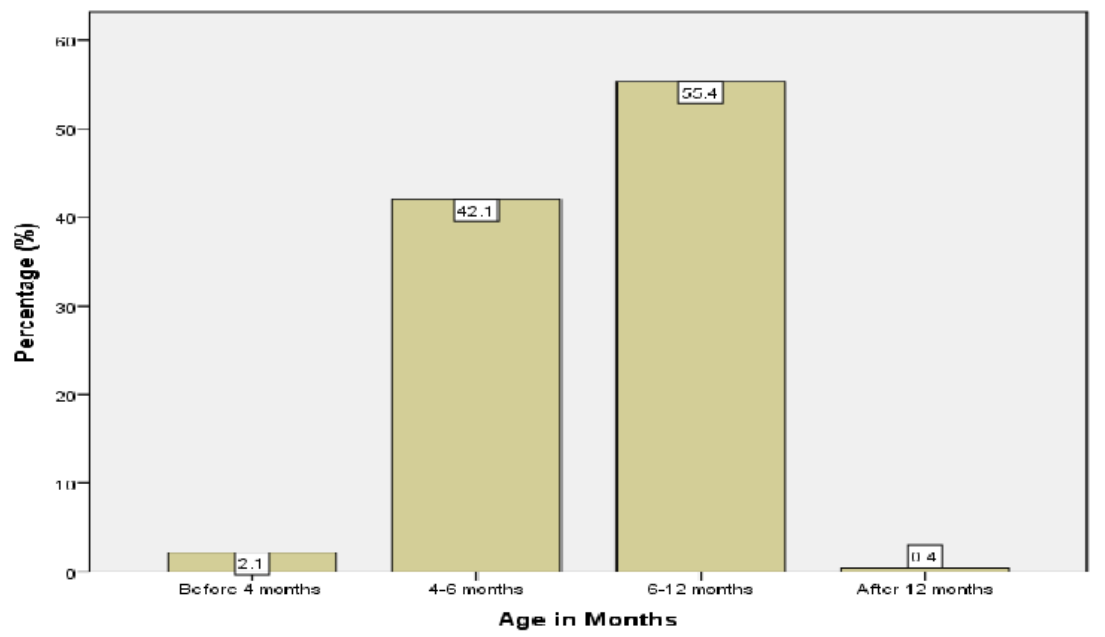

Figure 1: Age of introduction of other foods to children.

\section{Mother's Knowledge on Breast Milk}

In this study table 3 portrays respondent's knowledge taking into accounts the benefits that breast milk could deliver to infants in terms of nutrition, health, infant-mother relationships, contraceptive role and its availability. Generally, the highest proportions of mothers have good knowledge on the benefits that breastfeeding could give to their child. This study found that approximately about 95.4\% $(n=229), 94.2 \% \quad(n=223), 92.9 \% \quad(n=223), 89.6 \%$ $(n=215)$ and $86.3 \%(n=207)$ of mother believed that breast milk is nutritious, healthy, protective, encourage bonds between mother and child, and is the cheapest available at all time respectively. However, a relatively lower proportion of interviewees $(69.2 \%, n=116)$ think that $E B F$ could also have a contraceptive role for mothers provided that the menstrual cycle is not started.

\section{Factors Influencing Feeding Practices}

The influences of family, culture, community and other infrastructures on mothers breastfeeding practices has been presented in figure 2 below. About $41.6 \%$ of information on the importance of breastfeeding had obtained from Hospital Health Workers, while $39.0 \%$ of information has reached mothers through others such as a combination of Television, Radio, friends and culturally through experience from their family (figure $2 \& 3$ ).

Similarly, figure 4 has demonstrated the influence of friends, family and community in providing reliable information on the overall importance of child nutrition in general. Friends, family, community, radio, television, health centers and others separately or together were accountable for about $41.9 \%$ of mothers' source of information on child nutrition. 
Table 3: Mothers knowledge/response to quality of breast milk.

\begin{tabular}{|c|c|c|c|c|c|c|c|c|c|}
\hline \multirow{3}{*}{ Variables } & & \multirow{3}{*}{ Freq. } & \multirow{3}{*}{ Percent } & \multirow{3}{*}{$\begin{array}{l}\text { Valid } \\
\text { Percent }\end{array}$} & \multirow{3}{*}{$\begin{array}{c}\text { Cum. } \\
\text { Percent }\end{array}$} & \multicolumn{4}{|c|}{ Bootstrap for Percent $^{a}$} \\
\hline & & & & & & \multirow{2}{*}{ Bias } & \multirow{2}{*}{$\begin{array}{l}\text { Std. } \\
\text { Error }\end{array}$} & \multicolumn{2}{|c|}{$95 \% \mathrm{Cl}$} \\
\hline & & & & & & & & Lower & Upper \\
\hline \multirow{2}{*}{ Bf is Nutritious } & No & 1 & 0.4 & 0.4 & 4.6 & 0.0 & 0.4 & 0.0 & 1.3 \\
\hline & Yes & 229 & 95.4 & 95.4 & 100.0 & 0.0 & 1.4 & 92.5 & 97.9 \\
\hline \multirow{2}{*}{ Bf is Healthy } & No & 5 & 2.1 & 2.1 & 5.8 & 0.0 & 0.9 & 0.4 & 3.8 \\
\hline & Yes & 226 & 94.2 & 94.2 & 100.0 & 0.0 & 1.5 & 90.8 & 97.1 \\
\hline \multirow{2}{*}{$\mathrm{Bf}$ is Protective } & No & 7 & 2.9 & 2.9 & 7.1 & 0.0 & 1.1 & 1.3 & 5.4 \\
\hline & Yes & 223 & 92.9 & 92.9 & 100.0 & 0.0 & 1.8 & 89.2 & 96.3 \\
\hline \multirow{2}{*}{ Bf Encourages Bonding } & No & 4 & 1.7 & 1.7 & 10.4 & 0.0 & 0.7 & 0.4 & 3.3 \\
\hline & Yes & 215 & 89.6 & 89.6 & 100.0 & -0.1 & 2.0 & 85.0 & 92.9 \\
\hline \multirow{2}{*}{$\begin{array}{c}\text { Bf has Contraceptive } \\
\text { Benefits }\end{array}$} & No & 63 & 26.3 & 26.3 & 30.8 & -0.1 & 3.1 & 20.0 & 32.1 \\
\hline & Yes & 166 & 69.2 & 69.2 & 100.0 & 0.1 & 3.3 & 62.5 & 75.4 \\
\hline \multirow{2}{*}{ Breast Milk is Cheap } & No & 10 & 4.2 & 4.2 & 13.8 & 0.0 & 1.3 & 1.7 & 7.1 \\
\hline & Yes & 207 & 86.3 & 86.3 & 100.0 & -0.2 & 2.3 & 81.7 & 90.4 \\
\hline
\end{tabular}
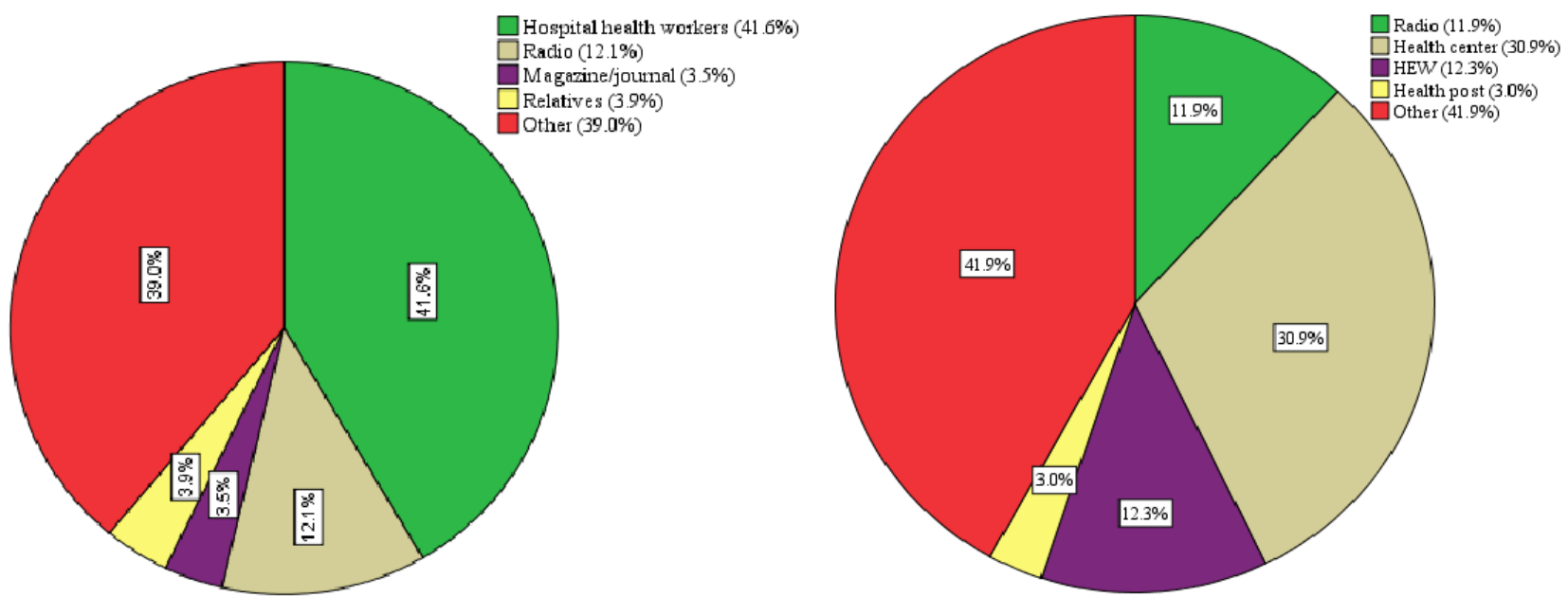

Figure 2: Source of information on breastfeeding among mothers.

Figure 3: Source of information on child nutrition.

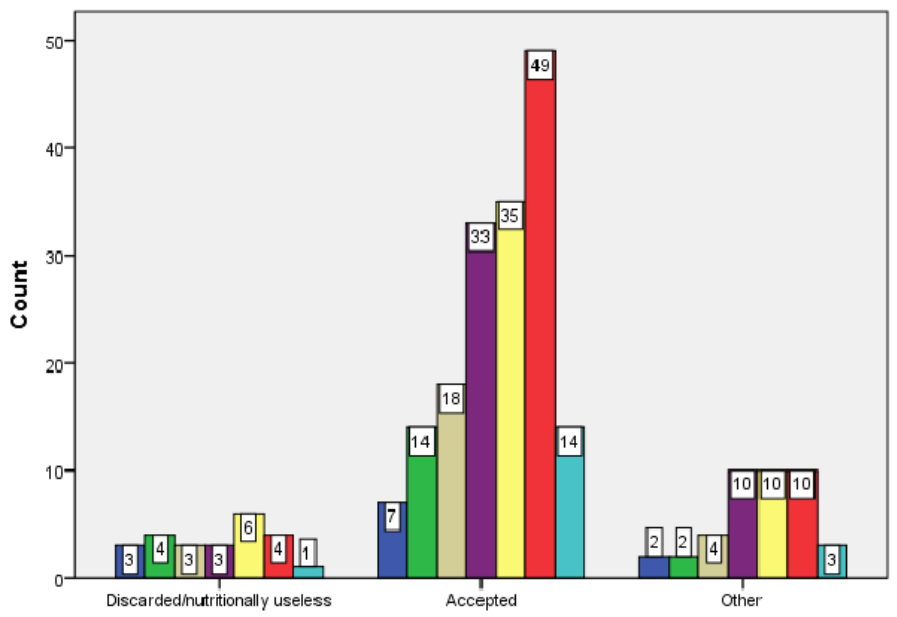

Figure 4: Attitude of mothers towards colostrums in relation to educational status.

Education/Family income on EBF /Initiation of Complementary Feeding

The Paired-Sample t-test procedure as presented in table 4 was carried out to produce a Pearson correlation and its significance (at $95 \% \mathrm{Cl}$ ) between education/family incomes with the duration of EBF/age additional food introduced to baby. Accordingly, the significant (2-tailed) values for the three paired tests were less than 0.05 , indicating the mean difference between mothers educational/family income status with duration of EBF/age at which additional food introduced were statistically significant. 
Table 4: Paired Samples T-test for the influences of mother's education/family income on the exclusive breastfeeding habit.

\begin{tabular}{|c|c|c|c|c|c|c|c|c|c|c|c|}
\hline & \multirow{3}{*}{ Variables } & \multicolumn{5}{|c|}{ Paired Differences } & \multirow{2}{*}{\multicolumn{2}{|c|}{$\begin{array}{c}\text { Paired Samples } \\
\text { Correlations }\end{array}$}} & \multirow{3}{*}{$\mathbf{t}$} & \multirow{3}{*}{ df } & \multirow{3}{*}{$\begin{array}{l}\text { Sig. } \\
\text { (2-tailed) }\end{array}$} \\
\hline & & \multirow{2}{*}{ Mean } & \multirow{2}{*}{$\begin{array}{l}\text { Std. } \\
\text { Dev. }\end{array}$} & \multirow{2}{*}{$\begin{array}{l}\text { Std. } \\
\text { Error } \\
\text { Mean }\end{array}$} & \multicolumn{2}{|c|}{$95 \% \mathrm{Cl}$} & & & & & \\
\hline & & & & & Lower & Upper & Corr. & Sig. & & & \\
\hline Pair 1 & $\begin{array}{l}\text { Education status - } \\
\text { Duration of EBF }\end{array}$ & 3.32 & 1.67 & 0.11 & 3.11 & 3.54 & 0.091 & 0.173 & 30.13 & 227 & 0.000 \\
\hline Pair 2 & $\begin{array}{l}\text { Family Income - } \\
\text { Duration of EBF }\end{array}$ & 1.39 & 1.24 & 0.08 & 1.23 & 1.56 & 0.092 & 0.172 & 16.75 & 222 & 0.000 \\
\hline Pair 3 & $\begin{array}{l}\text { Education Status - } \\
\text { Age Complementary } \\
\text { Food Introduced }\end{array}$ & 2.00 & 1.64 & 0.11 & 1.79 & 2.21 & 0.126 & 0.056 & 18.59 & 232 & 0.000 \\
\hline
\end{tabular}

\section{Attitude of Mothers towards Colostrums}

This study also found that educational level have some amount of influence on the attitude of mothers towards child feeding (colostrums) as presented in table 5 and figure 1. Approximately about $72 \%(n=170)$ of mothers accepts that colostrums is nutritious for infants, while significant proportion of mothers' $(41 \%)$ have no idea about what colostrums could provide to their child at all. Moreover, relatively few respondents $(21 \%)$ mother's also think that colostrums are nutritionally useless. Besides, the study also found that educated mothers have positive attitude towards colostrums than the less educated or uneducated mothers.

Table 5: Commonly perceived disadvantages of EBF among women in Nekemte town.

\begin{tabular}{|c|c|c|c|c|c|c|c|c|}
\hline \multirow{3}{*}{ Disadvantage of EBF } & \multirow{3}{*}{ Freq. } & \multirow{3}{*}{ Percent } & \multirow{3}{*}{$\begin{array}{l}\text { Valid } \\
\text { Percent }\end{array}$} & \multirow{3}{*}{$\begin{array}{l}\text { Cum. } \\
\text { Percent }\end{array}$} & \multicolumn{4}{|c|}{ Bootstrap for Percent $^{a}$} \\
\hline & & & & & \multirow[t]{2}{*}{ Bias } & \multirow{2}{*}{$\begin{array}{l}\text { Std. } \\
\text { Error }\end{array}$} & \multicolumn{2}{|c|}{$\begin{array}{c}95 \% \text { Confidence } \\
\text { Interval }\end{array}$} \\
\hline & & & & & & & Lower & Upper \\
\hline Breast milk not enough & 59 & 24.6 & 24.6 & 52.1 & 0.1 & 2.6 & 20.0 & 30.4 \\
\hline Breast milk causes infections & 2 & 0.8 & 0.8 & 52.9 & 0.0 & 0.6 & 0.0 & 2.5 \\
\hline Breast milk depletes mother & 60 & 25.0 & 25.0 & 77.9 & 0.1 & 3.1 & 19.2 & 31.2 \\
\hline No disadvantage & 51 & 21.3 & 21.3 & 99.2 & -0.1 & 2.8 & 15.0 & 27.5 \\
\hline Unknown & 2 & 0.8 & 0.8 & 100.0 & 0.0 & 0.6 & 0.0 & 2.1 \\
\hline
\end{tabular}

Perception of mothers' towards EBF and Weaning

Table 6 revealed that considerable proportions of mother $(24.6 \%$ and $25.0 \%)$ had perception that breast milk either not sufficient to EBF their baby or it may depletes mothers respectively. In contrary, about $21.3 \%$ of mothers appropriately perceived that EBF has no disadvantages at all for both mother and their child.

Table 6: Possible reasons for not EBF/short Bf duration/early wean practice

\begin{tabular}{|c|c|c|c|c|c|c|c|c|c|}
\hline \multirow{3}{*}{ Variables } & \multirow{3}{*}{ Reason } & \multirow{3}{*}{ Freq. } & \multirow{3}{*}{ Percent } & \multirow{3}{*}{$\begin{array}{l}\text { Valid } \\
\text { Percent }\end{array}$} & \multirow{3}{*}{$\begin{array}{l}\text { Cum. } \\
\text { Percent }\end{array}$} & \multicolumn{4}{|c|}{ Bootstrap for Percent } \\
\hline & & & & & & \multirow{2}{*}{\multicolumn{2}{|c|}{ Bias }} & \multicolumn{2}{|c|}{$95 \% \mathrm{Cl}$} \\
\hline & & & & & & & & Lower & Upper \\
\hline \multirow{4}{*}{ 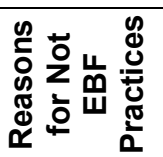 } & Mothers busy on job & 47.0 & 36.2 & 36.2 & 49.2 & -0.2 & 4.2 & 27.7 & 44.6 \\
\hline & Milk not enough & 37.0 & 28.5 & 28.5 & 77.7 & 0.1 & 3.8 & 21.5 & 36.2 \\
\hline & Baby failed to $\mathrm{Bf}$ & 4.0 & 3.1 & 3.1 & 80.8 & 0.1 & 1.4 & 0.8 & 6.2 \\
\hline & Unknown & 24.0 & 18.5 & 18.5 & 99.2 & 0.2 & 3.5 & 12.3 & 25.4 \\
\hline \multirow{4}{*}{ 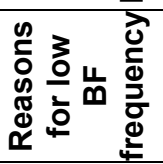 } & Short maternity leave & 17.0 & 13.1 & 13.1 & 30.0 & 0.0 & 2.9 & 7.7 & 18.5 \\
\hline & Un ideal work place & 65.0 & 50.0 & 50.0 & 80.0 & 0.0 & 4.4 & 41.6 & 58.5 \\
\hline & Unknown & 22.0 & 16.9 & 16.9 & 96.9 & 0.1 & 3.6 & 10.0 & 23.8 \\
\hline & No Response & 4.0 & 3.1 & 3.1 & 100.0 & 0.1 & 1.5 & 0.8 & 6.2 \\
\hline \multirow{7}{*}{ 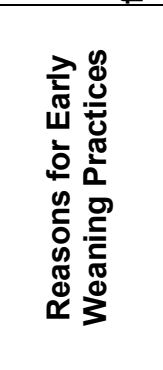 } & Insufficient milk & 37.0 & 28.5 & 28.5 & 28.5 & 0.3 & 3.7 & 20.8 & 35.4 \\
\hline & Starting job/work & 46.0 & 35.4 & 35.4 & 63.8 & 0.1 & 4.2 & 26.2 & 44.6 \\
\hline & Adopted child & 7.0 & 5.4 & 5.4 & 69.2 & -0.2 & 1.9 & 1.5 & 8.5 \\
\hline & $\begin{array}{l}\text { Lack of traditional } \\
\text { support and services }\end{array}$ & 11.0 & 8.5 & 8.5 & 77.7 & 0.1 & 2.5 & 3.8 & 13.8 \\
\hline & $\begin{array}{l}\text { Nipple of breast } \\
\text { soreness }\end{array}$ & 3.0 & 2.3 & 2.3 & 80.0 & -0.2 & 1.2 & 0.0 & 4.6 \\
\hline & $\begin{array}{l}\text { Dislike of breast } \\
\text { feeding }\end{array}$ & 4.0 & 3.1 & 3.1 & 83.1 & 0.1 & 1.5 & 0.8 & 6.9 \\
\hline & Unknown & 22.0 & 16.9 & 16.9 & 100.0 & -0.2 & 3.1 & 10.0 & 23.8 \\
\hline
\end{tabular}

This study has also identified the main reasons for no EBF practice, low duration of breastfeeding practices and reasons for early weaning practices among mothers in Nekemte town. As demonstrated in table 5 below about
$36.2 \%$ and $28.5 \%$ of mothers claims job and insufficient breast milk as their main reason for not following EBF practices respectively during the early life of the baby. Moreover, the highest proportions of mothers $(50.0 \%)$ 


\section{Wondu Garoma Berra}

have low breastfeeding frequency and duration, and this was associated with work place were babies not allowed or no privacy for breastfeeding.

Besides, as already indicated about $44.2 \%$ of mothers had introduced additional foods to their child before 6 month. In line with this, table 6 has presented that a considerable proportion of mothers approximately $35.4 \%$ and $28.5 \%$ respectively had claimed job/work and insufficient breast milk as their main reason for possible early weaning practices.

\section{DISCUSSION}

The study revealed that all mothers in Nekemte town breastfed their babies. A considerable proportion of
Sci. Technol. Arts Res. J., Oct-Dec 2013, 2(4): 78-86

mothers (84.2\%) who participated in the study Exclusively Breastfeeding (EBF) their babies for at least the first 4 to 6 months. There was no statistical association between mother's age and duration of exclusive breastfeeding (EBF), although most mothers' in the ages between 25 34 years has better attempt to EBF than those in the other age categories. Studies in Ghana on socio-cultural factors influencing infant feeding practices also showed that older women were more likely breastfed exclusively (SikaBright, 2010). However, the relation between mother's age and introduction of complementary food was statistically significant $(p=0.003)$ (Table 7). Relatively young mothers in the age of 15 to 24 were more inclined to introduce additional foods earlier before 6 months than mothers in the other age categories.

Table 7: Cross-tabulation of Socio-demographic Characteristic with Infant Feeding Practices.

\begin{tabular}{|c|c|c|c|c|c|c|c|c|c|}
\hline \multirow{2}{*}{\multicolumn{2}{|c|}{ Variables }} & \multicolumn{4}{|c|}{ Duration of EBF } & \multicolumn{4}{|c|}{$\begin{array}{l}\text { Age Complementary Feeding } \\
\text { Introduced }\end{array}$} \\
\hline & & $\begin{array}{l}\text { Up to } 6 \\
\text { months }\end{array}$ & $\begin{array}{c}6-12 \\
\text { months }\end{array}$ & $\begin{array}{c}12-23 \\
\text { months }\end{array}$ & $\begin{array}{c}\geq 24 \\
\text { months }\end{array}$ & $\begin{array}{c}\leq 4 \\
\text { months }\end{array}$ & $\begin{array}{c}4-6 \\
\text { months }\end{array}$ & $\begin{array}{c}\text { 6-12 } \\
\text { months }\end{array}$ & $\begin{array}{c}\text { After } 1 \\
\text { year }\end{array}$ \\
\hline \multirow{5}{*}{ Age in year } & $15-24$ & 28 & 2 & 0 & 0 & 0 & 16 & 15 & 0 \\
\hline & $25-34$ & 106 & 18 & 4 & 4 & 1 & 55 & 80 & 1 \\
\hline & $35-50$ & 52 & 2 & 3 & 2 & 2 & 25 & 30 & 0 \\
\hline & Above 50 & 6 & 1 & 0 & 0 & 2 & 2 & 4 & 0 \\
\hline & & $X^{2}=$ & $\begin{array}{l}487 \mathrm{df}= \\
\text { (2-sidec }\end{array}$ & $\begin{array}{ll}9 & \text { Asym } \\
= & 0.486\end{array}$ & Sig. & $X^{2}=2$ & $\begin{array}{l}619 \mathrm{df} \\
\text { (2-sided }\end{array}$ & $\begin{array}{l}9 \quad \text { Asyr } \\
=0.003\end{array}$ & Sig. \\
\hline \multirow{4}{*}{$\begin{array}{l}\text { Religion } \\
\text { Category }\end{array}$} & Christian & 153 & 23 & 5 & 5 & 4 & 79 & 108 & 0 \\
\hline & Museum & 34 & 0 & 1 & 1 & 1 & 16 & 18 & 1 \\
\hline & Others & 3 & 0 & 0 & 0 & 0 & 1 & 2 & 0 \\
\hline & & $X^{2}=5$ & $\begin{array}{l}604 \mathrm{df}= \\
\text { (2-sidec }\end{array}$ & $\begin{array}{ll}6 & \text { Asym } \\
= & 0.469\end{array}$ & Sig. & $X^{2}=5$ & $\begin{array}{l}940 \text { df }= \\
\text { (2-sided }\end{array}$ & $\begin{array}{ll}6 & \text { Asym } \\
= & 0.430\end{array}$ & Sig. \\
\hline \multirow{4}{*}{$\begin{array}{c}\text { Employment } \\
\text { Status }\end{array}$} & No & 131 & 14 & 3 & 2 & 5 & 65 & 83 & 1 \\
\hline & Yes & 61 & 9 & 4 & 4 & 0 & 33 & 46 & 0 \\
\hline & & $\mathrm{X}^{2}=$ & $\begin{array}{l}199 \mathrm{df}= \\
\text { (2-sidec }\end{array}$ & $\begin{array}{ll}3 & \text { Asym } \\
= & 0.158\end{array}$ & Sig. & $X^{2}=3$ & $\begin{array}{l}257 \mathrm{df}= \\
\text { (2-sided }\end{array}$ & $\begin{array}{ll}3 & \text { Asym } \\
= & 0.354\end{array}$ & Sig. \\
\hline & Less than 450 & 41 & 6 & 0 & 0 & 3 & 18 & 27 & 0 \\
\hline \multirow{5}{*}{$\begin{array}{l}\text { Family } \\
\text { Income }\end{array}$} & $450-999$ & 47 & 4 & 3 & 0 & 1 & 24 & 31 & 0 \\
\hline & $1000-1500$ & 40 & 9 & 2 & 3 & 1 & 19 & 35 & 1 \\
\hline & Above 1500 & 59 & 4 & 2 & 3 & 0 & 36 & 32 & 0 \\
\hline & & $x^{2}=1$ & $\begin{array}{l}2.595 \mathrm{df} \\
\text { (2-sidec }\end{array}$ & $\begin{array}{l}=9 \text { Asyn } \\
=0.182\end{array}$ & o.Sig. & $X^{2}=1$ & $\begin{array}{l}.614 \mathrm{df} \\
\text { (2-sided }\end{array}$ & $\begin{array}{lr}9 & \text { Asyn } \\
=0.181\end{array}$ & Sig. \\
\hline & Unmarried & 4 & 0 & 0 & 0 & 0 & 2 & 2 & 0 \\
\hline \multirow{5}{*}{$\begin{array}{l}\text { Marital } \\
\text { Status }\end{array}$} & Married & 182 & 22 & 7 & 6 & 4 & 93 & 125 & 1 \\
\hline & Divorced & 3 & 0 & 0 & 0 & 0 & 2 & 0 & 0 \\
\hline & Widowed & 1 & 1 & 0 & 0 & 0 & 1 & 1 & 0 \\
\hline & Other & 1 & 0 & 0 & 0 & 0 & 0 & 1 & 0 \\
\hline & & $\mathrm{X}^{2}$ & $\begin{array}{l}273 \mathrm{df}= \\
\text { (2-sidec }\end{array}$ & $\begin{array}{l}15 \text { Asyn } \\
=0.990\end{array}$ & Sig. & $X^{2}=$ & $\begin{array}{r}.594 \mathrm{df} \\
\text { (2-side }\end{array}$ & $\begin{array}{l}15 \text { Asyn } \\
=0.000\end{array}$ & Sig. \\
\hline
\end{tabular}

According to the present study religion don't have significant relationship with both duration of EBF and the age at which additional food was introduced to babies among mothers in Nekemte town. However, a case-study result from Ghana (Singh, 2010) on knowledge, attitude and practices showed that religion did have very significant relationship with duration of breastfeeding, reporting that greater percentage of Christian mother's breastfeed their babies for a longer duration (18 months on average).

There was no much significant association between marital statuses with the duration of EBF. However, the relation between marital status with the age at which mother's were introducing additional foods to their babies was highly significant $(p \leq 0.001)$. In this regards, unmarried and divorced mothers have more inclination to start complementary feeding early before 6 month than married women. Besides, there was no much association between family income/employment status with duration of EBF and age for initiation of complementary feeding. However, it's evident that employed mother's slightly inclined to practice short EBF duration or early initiation of additional foods.

In the other hand maternal education was significantly associated with their knowledge and practices of child nutrition $(P=0.000)$. As the educational level of 


\section{Wondu Garoma Berra}

mothers/caretakers increase the knowledge/practice of child nutrition such as duration of EBF and age at which complementary food introduced also improved. This may suggest that education is associated with reduced rate of child nutrition. Several studies including Sendeku and Agegnehu (2007) showed that better educational status of mothers clearly improves the nutritional status of children. Studies carried out in developing countries strongly suggested that maternal education and nutritional knowledge were positively associated with their under-five children nutritional status, particularly the knowledge on starting time of breastfeeding after birth, importance of colostrums, age of complementary feeding introduction and knowledge on causes of malnutrition. Another investigator from Ghana (Sika-Bright, 2010) has found a strong positive correlation between maternal age and maternal education level and breastfeeding initiation and duration. More specifically, older and better educated women are preferred infant breastfeeding, generally longer breastfeeding duration and more likely to breastfed exclusively.

The overall knowledge of mother's on the quality of breast milk was found to be good among the women's who participated in this study. About 95.4\%, 94.2\%, $92.9 \%, 89.6 \%$ and $86.3 \%$ of mother's knows that breast milk is nutritious, healthy, protective, encourage strong mother-child relation and cheaply available for their child, respectively. According to several sources including Ethiopian Federal Ministry of Health protocol for the management of severe acute malnutrition ( $\mathrm{MOH}, 2007)$, breastfeeding helps to protect babies and young children against dangerous illnesses. It also creates a special bond between mother and child. It's also well known that exclusive breastfeeding (EBF) can give a woman more than 98 percent protection against pregnancy for six months after giving birth -but only if her menstrual periods have not resumed, if her baby breastfeeds frequently day and night, and if the baby is not given any other food or drinks, or a pacifier or dummy. However, the knowledge of mothers on contraceptive role of EBF was only about $69.2 \%$. Similar study result reported by Singh (2010) regarding mother's response on quality (benefits) of breast milk has revealed that, about $100 \%, 97.0 \%, 80.0 \%$, $99.0 \%, 32.0 \%$ and $81.0 \%$ of mothers has responded that breast milk is nutritious, healthy, protects from diseases, encourage bonding, plays contraceptive role and is cheaply available respectively.

In many ways, even though breastfeeding is a universal practice, there are cultural aspects that vary considerably about colostrums which are the most nutritious part of breast milk and are secreted for the first two days and on the $3^{\text {rd }}$ and $4^{\text {th }}$ days the secretion changes to normal breast milk. This particular study also reveled that attitude of mothers towards colostrums is good. Approximately, $72.0 \%$ of mothers had expressed their attitude towards colostrums positively and consider it as nutritious for their infants.

The study has revealed that perception of mother's towards EBF for the first six months is also good (84.2\%) among Nekemte town women who participated in the study indicating that knowledge is an important factor that influences perception and practices in breastfeeding. About $42.1 \%$ mothers has initiated additional food (complementary feeding) with in the first 4 to 6 months of
Sci. Technol. Arts Res. J., Oct-Dec 2013, 2(4): 78-86

infants life, while $55.4 \%$ introduced complementary feeding at 6 to 12 months of the infants life. With regards to initiation of child feeding, $64.2 \%$ of mothers use cow milk, porridge and gruel as the most common type of complementary food for their babies. Surprisingly, about $92.4 \%$ of mother's perceived that breastfeeding should continue together with complementary feeding for at least 2 years. This is in total agreement with recommendation from the Federal Ministry of Health of Ethiopia $(\mathrm{EMOH}$, 2004). The national strategy clearly highlighted that an appropriate complementary feeding promotes growth and prevents stunting among children between 6 and 24 months of age.

Furthermore, the investigation has identified also the most commonly perceived disadvantages of mothers towards child feeding practices among women in Nekemte town. Although, considerable proportion of mother's $(21.3 \%)$ perceived that EBF has no disadvantages, about $24.6 \%$ of women has showed their worries that breast milk may not be sufficient while $25.0 \%$ think it may depletes mothers. Besides, $36.2 \%$ of women complained mothers busy on job and $28.5 \%$ of mother's claimed insufficient breast milk as possible reason for not following EBF practices. Study result from Mbarara (Uganda) on perception and knowledge of EBF among women similarly showed that the major disadvantages of EBF perceived was that it depletes mothers' health $(21.1 \%)$ while the largest proportion of mother's perceived EBF has no disadvantages (Petit, 2008).

The study also has found that high proportion of mothers, approximately $63.1 \%$ accused for non suitable working environments for babies breastfeeding and short maternity leave as the main reason for low breastfeeding duration. More specifically, about $28.5 \%$ of women have raised insufficient breast milk as the main possible reason for early weaning practices. Study result reported from Bangladesh on the factors influencing the weaning knowledge of mothers of under five children (Khan et al., 2007) has showed that most babies in developing countries are given breast milk although the time of initiation, duration and supplementation vary widely. Moreover, the study also indicated that the primary reasons for early weaning of food for babies were wrong perception of mothers on insufficient of breast milk or refusal of babies to suckle.

In this study the influence of mother's education status and family socio-economic status on duration of EBF habit and initiation of additional food was tested using Paired Sample T-test. Accordingly, the relation between mother's educational status/family income and duration of EBF/age complementary food introduced were found to be significant $(p=0.000)$, although the correlation between looks relatively weak. This result supports the idea of Sink-Bright (2010) reported as mothers' level of education and employment statuses were found to be significantly related to infants feeding practices. The report extends that mothers with higher educational degrees were not EBF with the assumption that educated mothers are mostly employed and are more likely to mixed feeding than EBF in the first six months of their child's life.

Finally, the study has showed also the influence of family and community including friends, relatives, health institutions and media in providing information on child 


\section{Wondu Garoma Berra}

feeding practices. The role of hospital health workers in providing information to mother's about breastfeeding practices was found to be very significant (41.6\%) followed by media (radio, TV) in combination which were accountable for $39.0 \%$. In general, media and relatives in combination take the lion share $(41.9 \%)$ in providing information on child nutrition followed by health centers $(30.9 \%)$ and HEW (12.3\%). Similarly study result based in Arba Minch town and its area has showed that the major sources of nutrition information for mothers/caretakers were reported (Sendeku and Agegnehu, 2007) to be health centers $(39 \%)$, at home by $\mathrm{HEW}(34 \%)$, radio $(17 \%)$ and health posts $(10 \%)$. It's therefore, the major source of information's about child nutrition for mothers in Nekemte town were health institutions, while the role of media and HEW was still so significant.

\section{CONCLUSION}

In this study, it is apparent that mothers/caretakers in the sample selected from Nekemte town generally have good knowledge and practices regarding child nutrition. Despite the declining trends of breastfeeding worldwide, the prevalence of breastfeeding practices in Nekemte town is quite adequate. All mothers in Nekemte town breastfed their babies, although the duration of EBF considerably varies among mothers.

Based on the analysis of the data, the knowledge and practices of infant feeding is affected by certain demographic and socio-cultural factors such as education and family income. Maternal education was significantly associated with their knowledge and practices of child nutrition $(p=0.000)$. As the educational level of mothers/caretakers increase the knowledge/practice of child nutrition particularly duration of EBF and age at which complementary food introduced also improved. Relatively young mothers in the age of 15 to 24 were more inclined to introduce additional foods earlier before 6 months than mothers in the other age categories, implying that although their knowledge about the importance of breastfeeding is good, their practices do not conform to the knowledge they seem to have.

Besides, the study has revealed that perception of mother's towards EBF for the first six months is also good $(84.2 \%)$ among Nekemte town women who participated in the study which indicates that knowledge is an important factor that influences perception and practices in breastfeeding. On the other hands, about $42.1 \%$ mothers has initiated complementary feeding with in the first 4 to 6 months of infants life, while $55.4 \%$ introduced complementary feeding at 6-12 months of the infants life.

This investigation has identified also the most commonly perception of mothers towards child feeding practices among women. Accordingly, about $24.6 \%$ of mothers wrongly perceived breast milk is not sufficient or they think it depletes mothers. About $36.2 \%$ of women complained mothers busy on job and $28.5 \%$ of mother's perceived wrongly that insufficient breast milk as possible reason for not following EBF practices. However, the perception that EBF is not disadvantageous to the child was also substantial (21.3\%). Besides, $63.1 \%$ accused for non suitable working environments for babies breastfeeding and short maternity leave as the main reason for low breastfeeding duration.
Sci. Technol. Arts Res. J., Oct-Dec 2013, 2(4): 78-86

The study also has clearly identified influence of family and communities including friends, relatives, health institutions and media in providing information on child feeding practices particularly breastfeeding. The health institutions provided a good source of information on child nutrition for mothers in Nekemte town. Therefore it can be concluded that strengthening this mode of providing information can help to raise the prevalence of good child nutrition and EBF significantly.

\section{REFERENCE}

Anyango, J.L. and Ayieko M.A. (2011). Evaluation of Nutrition Knowledge and Perception of Good Food among Nursery School Pupils in Kisumu Municipality-Kenya. Advance Journal of Food Science and Technology 165-172.

Awogobenja, M.Dehinde and Ugwuona, Fabian.U (2010). Feeding Practices and Nutritional Status of Under-five Children in Nasarawa State, Nigeria. PAT 6(1): 23-35.

EMOH (2004). National Strategy for infant and young child feeding. Family Health Department.

$\mathrm{EMOH}$ (2007). Ethiopia protocol for the management of severs acute malnutrition. Ministry of Health, Ethiopia. March 2007.

Ethiopia national nutrition strategy (2009), Review and analysis of progress and gap: One year on. May 2009. Pp $1-42$.

Gemeda Daba, Fekadu Beyene, Wondu Garoma and Habtamu Fekadu (2013). Assessment of Nutritional Practices of Pregnant Mothers on Maternal Nutrition and Associated Factors in Guto Gida Woreda, East Wollega Zone, Ethiopia. Science, Technology and Arts Research Journal 2(3): 105-113

Khan, M.A.S., Hassain, M.M. and Banik, A.K. (2007). Factors influencing the weaning knowledge of mothers of under five children: A hospital based study. The ORION Medical Journal 28: 487-489.

Langi and Grace K. L (2008). Knowledge and perception of mothers about nutritional status of children under five years of age in Bahu Health Center, Malayang Sub district, Manado City, North Sulawesi Province, Indonesia. MSc Thesis, Manihol University.

Petit, A.I. (2008). Perception and knowledge on exclusive breastfeeding among women attending antenatal and postnatal clinic -A study from mbarara hospital, Uganda. Dar Es Salaam Medical Students' Journal 16(1): 27-30.

Sendeku and Agegnehu Gebru (2007). Perception and practice of mothers/caretakers on child nutrition (0-56) in Arba Minch Zuria. 2nd Annual Conference of Food and Nutrition Society (FoNSe). Addis Ababa: Ethiopian Health and Nutrition Research Institute, 64-86.

Sika-Bright (2010). Socio-cultural factors influencing infants feeding practices of mothers attending Welfare clinic in Cape Coast. January 2010. Pp 1-19.

Singh, B. (2010). Knowledge, Attitude and Practice of Breastfeeding -A case study. European Journal of Scientific Research 40(3): 404-422.

Waqar Azim., Haleema Shafi., Shaukat M. Qureshi., Tariq S. Sheikh., Saad Azim., Farzana Hayat. (2005). Perceptions and practices of mothers regarding child feeding. Biomedica 21(2): 71-75. 